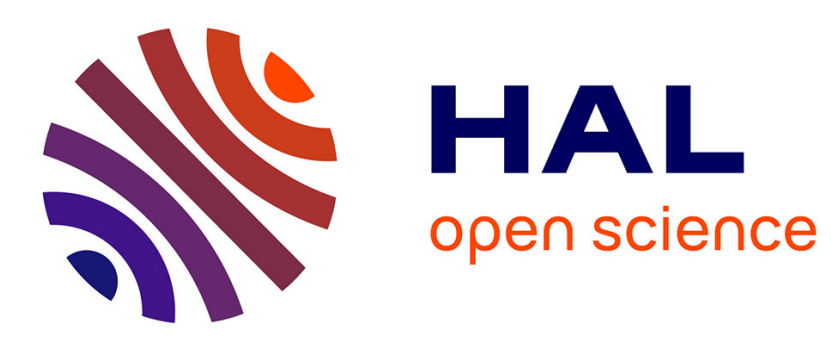

\title{
First-order shear deformation plate models for functionally graded materials
}

\author{
T. K. Nguyen, Karam Sab, Guy Bonnet
}

\section{To cite this version:}

T. K. Nguyen, Karam Sab, Guy Bonnet. First-order shear deformation plate models for functionally graded materials. Composite Structures, 2008, 83 (1), pp.25-36. hal-00691028

\section{HAL Id: hal-00691028 \\ https://hal.science/hal-00691028}

Submitted on 16 Jan 2016

HAL is a multi-disciplinary open access archive for the deposit and dissemination of scientific research documents, whether they are published or not. The documents may come from teaching and research institutions in France or abroad, or from public or private research centers.
L'archive ouverte pluridisciplinaire HAL, est destinée au dépôt et à la diffusion de documents scientifiques de niveau recherche, publiés ou non, émanant des établissements d'enseignement et de recherche français ou étrangers, des laboratoires publics ou privés. 


\title{
First-order shear deformation plate models for functionally graded materials
}

\author{
Trung-Kien Nguyen ${ }^{\mathrm{a}}$, Karam Sab ${ }^{\mathrm{a}, *}$, Guy Bonnet ${ }^{\mathrm{b}}$ \\ a Institut Navier, LAMI (ENPC/LCPC), Ecole Nationale des Ponts et Chaussées, 6-8 Avenue Blaise Pascal, Cité Descartes, \\ 77455 Marne-La-Vallée, France \\ b Université de Marne-La-Vallée, Laboratoire de Mécanique (Institut Navier) 5 bd Descartes, 77454 Marne-La-Vallée, France \\ Abstract
}

In this paper, first-order shear deformation plate models for modelling structures made of functionally graded materials are proposed. Identification of transverse shear factors is investigated through these models by energy equivalence. The transverse shear stresses are derived from the expression of membrane stresses and equilibrium equations. Using the obtained transverse shear factor, a numerical analysis is performed on the examples of a simply supported square plate and of a cylindrical bending sandwich plate clamped at both ends. The material properties are assumed to be isotropic at each point and vary through the thickness according to a power law distribution. The numerical results of the static analysis are compared to available solutions from previous studies.

Keywords: Functionally graded material; First-order shear deformation plate theory; Shear correction factor

\section{Introduction}

The multilayered materials are used in many structures. In conventional laminated composite structures, homogeneous elastic laminae are bonded together to obtain enhanced mechanical and thermal properties. The main inconvenience of such an assembly is to create stress concentrations along the interfaces, more specifically when high temperatures are involved. This can lead to delaminations, matrix cracks, and other damage mechanisms which result from the abrupt change of the mechanical properties at the interface between the layers. One way to overcome this problem is to use functionally graded materials within which material properties vary continuously. The concept of functionally graded material (FGM) was proposed in 1984 by the material scientists in the Sendai area of Japan [13]. The FGM is a composite material whose composition varies according to the required performance. It can be produced with a continuously graded variation of the volume fractions

\footnotetext{
* Corresponding author. Tel.: +33164153736.

E-mail address: sab@lami.enpc.fr (K. Sab).
}

of the constituents. That leads to a continuity of the material properties of FGM: this is the main difference between such a material and an usual composite material. The FGM is suitable for various applications, such as thermal coatings of barrier for ceramic engines, gas turbines, nuclear fusions, optical thin layers, biomaterial electronics, etc.

The composite plates are studied widely in the literature (a review of the plate theories can be found in Ghugal and Shimpi [9]). Plate models for the functionally graded materials have been studied with analytical and numerical methods. Various approaches have been developed to establish the appropriate analysis of the functionally graded (FG) plates. The model based on classical plate theory (CPT) of Love-Kirchhoff was applied by Chi and Chung $[5,6]$ for the FGM. They developed the analytical solution for simply supported FG plates subjected to mechanical loads. A finite element formulation based on the CPT was studied by $\mathrm{He}$ et al. [12] to control the shape and vibration of the FG plate with integrated piezoelectric sensors and actuators. In practice, this model is not used for thick plates which have an important contribution of the shear deformation energy. Several authors studied the behavior of thick FG plates. 
They suggested models that take into account the transversal shear effect, by using the first-order shear deformation theory (FSDT) $[19,16]$ and higher-order shear deformation theories [20,21]. Praveen and Reddy [17] examined the nonlinear static and dynamic responses of functionally graded ceramic-metal plates using the first-order shear deformation theory (FSDT) and the von Karman strain (see Reddy $[20,21])$. Croce and Venini [15] formulated a hierarchic family of finite elements according to the Reissner-Mindlin theory. The model of FSDT plate is the simplest model that accounts for the transverse shear strains. It requires shear correction coefficients to compute transverse shear forces. To avoid this difficulty, several authors proposed the higher-order shear deformation theory and applied it to FGM. Reddy [22] developed the Navier's solutions for functionally graded plates using the third-order shear deformation plate theory (TSDT) and an associated finite element model. Cheng and Batra [3] used also the theory of Reddy (TSDT) for studying the buckling and steady state vibrations of a simply supported functionally graded polygonal plate. Moreover, the sinusoidal shear deformation theory (SSDT) of Zenkour [34-36] was used for FG plates. By using the theory himself, Zenkour [33] presented Navier's analytical solution of FG plates. Furthermore, he presented the analysis of FG sandwich plates for the deflection, stresses, buckling and free vibration in [37,38]. In the higherorder shear deformation theory, the transverse shear stresses are taken into account throughout the thickness and consequently no transversal shear correction factors are needed. For the thick FG plates whose thickness is not negligible, when compared to the side length, the three-dimensional models for static and dynamic problems can be used. Cheng and Batra [4] studied thermomechanical deformations of the FG plates. Elishakoff et al. [7] used the Ritz's method to derive the three-dimensional governing equation for the all-round clamped FG plates. A discrete layer approach was proposed by Ramirez et al. [18] for the static analysis of three-dimensional FG plates. For analysis of functionally graded beams, Reddy [23] also presented a FG finite element beam model by using the FSDT (Timoshenko beam) and the TSDT. Satchi and Bhavani [26] analyzed the sandwich beam with a functionally graded core for which they proposed an elasticity solution.

The models based on the first-order shear deformation theory (FSDT) are very often used owing to their simplicity in analysis and programming. It requires however a convenient value of the shear correction factor. In practice, this coefficient has been assumed to be given by $5 / 6$ as for homogeneous plates. This value is a priori no longer appropriate for functionally graded material analysis due to the position dependence of elastic properties.

The primary objective of this paper is thus to identify the shear correction coefficients for the FSDT models made of functionally graded materials. Applications are presented for a simply supported plate and for a sandwich panel which is clamped at both ends. The influence of this factor on the static response is then presented. The material elastic properties are supposed to be isotropic and varying through the thickness according to a power-law function of the position.

\section{Theoretical formulation}

Consider a FSDT plate model (Fig. 1) having a thickness $h$ which is located within a domain $\Omega=\omega \times]-\frac{h}{2}, \frac{h}{2}$ [, $h \in R^{+} . \omega \in R^{2}$ is a area possessing a boundary with a suitable regularity $\partial \omega$. The top and bottom surfaces of the plate are denoted by $\Gamma^{ \pm}=\omega \times\left\{ \pm \frac{h}{2}\right\}=\{x, y \in \Omega$, $\left.z= \pm \frac{h}{2}\right\}$. The plate is made of a functionally graded material which is constituted by a mixture of ceramic and metallic components. The material properties vary through the plate thickness according to the volume fractions of the constituents. All formulations are performed under the assumption of a linear elastic behavior and small deformations of materials. The gravity is not taken into account.

\subsection{Stress fields}

The displacement field of the first-order shear deformation theory (FSDT) and the basic equations of the plate model can be found in $[20,21,29]$. This section presents the steps used in order to compute the shear stiffnesses of the FG plates. The appropriate shear correction factors will then be obtained. The sandwich panel model will be studied as a special case. In this section, the Greek indices are assumed to range within $\{1,2\}$ while the Latin indices take values $\{1,2,3\}$.

\subsubsection{In-plane stresses}

The generalized stresses associated to the in-plane stress field $\sigma_{\alpha \beta}(N, M)$ can be defined as follows:

$$
\begin{aligned}
& N_{\alpha \beta}(x, y)=\int_{-h / 2}^{h / 2} \sigma_{\alpha \beta}(x, y, z) \mathrm{d} z, \\
& M_{\alpha \beta}(x, y)=\int_{-h / 2}^{h / 2} z \sigma_{\alpha \beta}(x, y, z) \mathrm{d} z .
\end{aligned}
$$

The generalized strains are given by,

$$
\begin{aligned}
& \epsilon_{\alpha \beta}^{0}(x, y)=\frac{1}{2}\left(u_{\alpha, \beta}+u_{\beta, \alpha}\right)(x, y), \\
& \chi_{\alpha \beta}(x, y)=\frac{1}{2}\left(\theta_{\alpha, \beta}+\theta_{\beta, \alpha}\right)(x, y),
\end{aligned}
$$

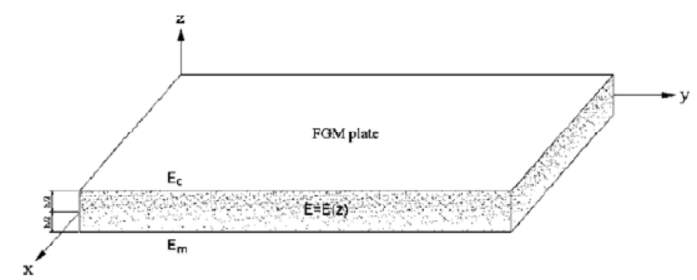

Fig. 1. Geometry of the functionally graded plate. 
where the comma indicates partial differentiation with respect to the coordinate subscript that follows, $u$ and $\theta$ the displacement and rotation of the FSDT. The strain is assumed to be linear through the thickness of the FG plate,

$\epsilon_{\alpha \beta}(x, y, z)=\epsilon_{\alpha \beta}^{0}(x, y)+z \chi_{\alpha \beta}(x, y)$.

The membrane strains and in-plane stresses are related by the constitutive equation,

$\sigma_{\alpha \beta}(x, y, z)=C_{\alpha \beta \gamma \delta}(z)\left(\epsilon_{\gamma \delta}^{0}(x, y)+z \chi_{\gamma \delta}(x, y)\right)$,

where $C_{\alpha \beta \gamma \delta}(z)$ are the components of the reduced elasticity tensor at location $z$. Substituting (4) into (1) leads to:

$N_{\alpha \beta}(x, y)=A_{\alpha \beta \gamma \delta} \epsilon_{\gamma \delta}^{0}(x, y)+B_{\alpha \beta \gamma \delta} \chi_{\gamma \delta}(x, y)$,

$M_{\alpha \beta}(x, y)=B_{\alpha \beta \gamma \delta} \epsilon_{\gamma \delta}^{0}(x, y)+D_{\alpha \beta \gamma \delta} \chi_{\gamma \delta}(x, y)$,

where $A_{\alpha \beta \gamma \delta}, B_{\alpha \beta \gamma \delta}, D_{\alpha \beta \gamma \delta}$ are the stiffnesses of the plate which are given by,

$\left(A_{\alpha \beta \gamma \delta}, B_{\alpha \beta \gamma \delta}, D_{\alpha \beta \gamma \delta}\right)=\int_{-h / 2}^{h / 2}\left(1, z, z^{2}\right) C_{\alpha \beta \gamma \delta}(z) \mathrm{d} z$.

It can be noticed that, unlike for a homogeneous symmetrical isotropic plate where the coupling stiffnesses $B_{\alpha \beta \gamma \delta}$ are null, the $B_{\alpha \beta \gamma \delta}$ are present in the constitutive equation for the non-symmetrical functionally graded plates. The membrane strains are finally:

$\epsilon_{\alpha \beta}^{0}(x, y)=a_{\alpha \beta \gamma \delta} N_{\gamma \delta}(x, y)+b_{\alpha \beta \gamma \delta} M_{\gamma \delta}(x, y)$,

$\chi_{\alpha \beta}(x, y)=b_{\alpha \beta \gamma \delta} N_{\gamma \delta}(x, y)+d_{\alpha \beta \gamma \delta} M_{\gamma \delta}(x, y)$,

where $\left(a_{\alpha \beta \gamma \delta}, b_{\alpha \beta \gamma \delta}, d_{\alpha \beta \gamma \delta}\right)$ are the components of the compliance matrix. The matrices $C, A, B, D, a, b$ and $d$ can be explicitly expressed in terms of the functions $E(z)$ and $v(z)$ describing the Young modulus and the Poisson's ratio at $z$, respectively. Moreover, it appears that the matrix $b$ is symmetric owing to the fact that the material elastic properties are isotropic. Substituting (7) in (4) leads to:

$\sigma_{\alpha \beta}(x, y, z)=n_{\alpha \beta \gamma \delta}(z) N_{\gamma \delta}(x, y)+m_{\alpha \beta \gamma \delta}(z) M_{\gamma \delta}(x, y)$,

where $n_{\alpha \beta \gamma \delta}(z), m_{\alpha \beta \gamma \delta}(z)$ are the components of the localization tensors that are expressed as:

$n_{\alpha \beta \gamma \delta}(z)=C_{\alpha \beta \varepsilon \varphi}(z)\left(a_{\varepsilon \varphi \gamma \gamma \delta}+z b_{\varepsilon \varphi \gamma \gamma \delta}\right)$,

$m_{\alpha \beta \gamma \delta}(z)=C_{\alpha \beta \varepsilon \varphi}(z)\left(b_{\varepsilon \varphi \gamma \delta}+z d_{\varepsilon \varphi \gamma \delta}\right)$.

\subsubsection{Transverse shear stresses}

The calculation of the transverse shear stresses from the constitutive equation is not realistic because of the assumption of a constant shear strain through the thickness of the plate. The transverse shear stresses are derived classically from the equilibrium equation. The equilibrium equation in $\Omega$ allows to determine the shear stresses $\sigma_{\alpha 3}$ which are given by:

$\sigma_{\alpha 3}=-\int_{-h / 2}^{z} \sigma_{\alpha \beta \beta \beta} \mathrm{d} \xi$, where the integration coefficients have been selected to satisfy the boundary condition for shear stresses at the upper and lower faces of the plate. By substituting (8) into (10), the following relationship is obtained:

$\sigma_{\alpha 3}=\tilde{n}_{\alpha \beta \gamma \delta}(z) N_{\gamma \delta, \beta}(x, y)+\tilde{m}_{\alpha \beta \gamma \delta}(z) M_{\gamma \delta, \beta}(x, y)$,

where,

$\tilde{n}_{\alpha \beta \gamma \delta}(z)=-\int_{-h / 2}^{z} C_{\alpha \beta \varepsilon \varphi}(\xi)\left[a_{\varepsilon \varphi \gamma \delta}+\xi b_{\varepsilon \varphi \gamma \delta}\right] \mathrm{d} \xi$,

$\tilde{m}_{\alpha \beta \gamma \delta}(z)=-\int_{-h / 2}^{z} C_{\alpha \beta \varepsilon \varphi}(\xi)\left[b_{\varepsilon \varphi \gamma \delta}+\xi d_{\varepsilon \varphi \gamma \delta}\right] \mathrm{d} \xi$,

$\tilde{n}_{\alpha \beta \gamma \delta}=\tilde{n}_{\gamma \delta \alpha \beta}=\tilde{n}_{\beta \alpha \gamma \delta}, \quad \tilde{m}_{\alpha \beta \gamma \delta}=\tilde{m}_{\gamma \delta \alpha \beta}=\tilde{m}_{\beta \alpha \gamma \delta}$

It is noted that the expression (12) is obtained due to the uniform properties of the material in the plane of the laminate $\left(n_{\alpha \beta \gamma \delta, \beta}=0, m_{\alpha \beta \gamma \delta, \beta}=0\right)$.

A direct computation of the shear stresses within Eq. (10) will require the second-order derivatives of the displacement. For finite element methods, several authors (Lee and Lee [14], Sze [28], Zenkiewicz and Zhu [40], Rolfes and Rohwer [24,25]) used a method of postprocessing based on the three-dimensional equilibrium equations or a predictor-corrector approach or simplified assumptions. A simplifying assumption [24,25] which is used thereafter, enables the computation of shear stresses from transverse shear forces. This process allows to comply to boundary conditions on the transverse shear stresses and to save an order of derivation. A last simplification is achieved by using a cylindrical bending assumption. Assuming cylindrical bending around the axis $y$, using the equilibrium equations of the plate $\left(N_{\alpha \beta, \beta}=0, M_{\alpha \beta, \beta}-Q_{\alpha}=0\right)$ and omitting the weak terms ( $N_{22,1}$ and $M_{22,1}$ ), leads to:

$\sigma_{x z}(x, z)=\tilde{m}_{1111}(z) Q_{x}(x)$,

with $\tilde{m}_{1111}(z)$ given in (12). Practically, this relation is very often used to compute the shear stress of the homogeneous model with a quadratic form of $\tilde{m}_{1111}(z)$, especially when commercial finite element packages are used.

\subsection{Shear correction factors}

It is well-known that the models based on the first-order shear deformation theory require a correct value of the shear correction factors to compute the shear force. Several authors made contributions in order to improve the models used for the FSDT. Hutchinson [11], Gruttmann and Wagner [10] presented a new formula in order to compute the shear coefficients of different cross-sections of a Timoshenko's beam. The discussion of this topic for the plate and shell problems can be found in $[1,2,25,27,32]$. In this paper, the shear coefficients are studied by considering the shear deformation energy.

The shear forces $\left(Q_{x}, Q_{y}\right)$ are related to the average shear strains $\left(\gamma_{x z}, \gamma_{y z}\right)$ by, 


$$
\left\{\begin{array}{l}
Q_{y} \\
Q_{x}
\end{array}\right\}=\left[\begin{array}{ll}
H_{44} & H_{45} \\
H_{45} & H_{55}
\end{array}\right]\left\{\begin{array}{l}
\gamma_{y z}^{0} \\
\gamma_{x z}^{0}
\end{array}\right\},
$$

where $H_{i j}(i, j=4,5)$ are the shear stiffnesses. For isotropic materials, there is no coupling between the shear deformations in two directions, i.e., $H_{45}=0$ and $H_{44}=H_{55}$. Therefore, it is sufficient to identify only one of the components $\mathrm{H}_{55}$ or $\mathrm{H}_{44}$.

By using the shear stress defined in (13), the shear deformation energy per unit middle surface area is then given by the following expression:

$\Pi_{s}=\frac{1}{2} Q_{x}^{2} \int_{-h / 2}^{h / 2} \frac{\left[\tilde{m}_{1111}(z)\right]^{2}}{G(z)} \mathrm{d} z$,

where $G(z)=E(z) /(2(1+v(z)))$ is the transverse shear modulus at location $z$. Furthermore, the shear deformation energy per unit middle surface area is expressed by using the average shear deformation,

$\Pi_{s m}=\frac{1}{2} Q_{x} \gamma_{x z}^{0}=\frac{1}{2} \frac{Q_{x}^{2}}{H_{55}}$.

The balance of the shear energy enables us to deduce,

$H_{55}=\left(\int_{-h / 2}^{h / 2} \frac{\left[\tilde{m}_{1111}(z)\right]^{2}}{G(z)} \mathrm{d} z\right)^{-1}$,

where $H_{55}$ is the improved shear stiffness for FG plates. The shear correction coefficients are finally obtained from:

$k_{55}=\frac{H_{55}}{\int_{-h / 2}^{h / 2} G(z) \mathrm{d} z}$.

The shear correction factor is equal to $5 / 6$ for homogeneous plates assuming a parabolic variation of the shear stress and a priori relations (18), (17) and (12) will lead to different values for the FGM. Moreover, the use of the improved shear stiffnesses in Eq. (17) will provide a better evaluation of transverse shear forces in (14).

\section{Applications}

The numerical applications of the FSDT model are performed with two examples. The first test is the study of the cylindrical bending of a clamped-clamped sandwich panel. A comparison is performed with solutions obtained from discrete finite element model and other cylindrical bending plate models. In the second example, a simply supported plate is studied. Navier's analytical solution is achieved and compared to the FSDT, TSDT, SSDT solutions and to a three-dimensional discrete finite element solution.

\subsection{Sandwich panel with functionally graded faces}

\subsubsection{Material distribution}

Consider the 3-layers sandwich strip shown in Fig. 2. The face layers are made of a ceramic-metal isotropic material whose properties vary smoothly through the

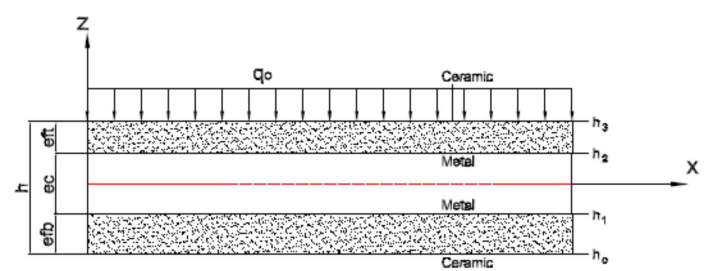

Fig. 2. Geometry of the sandwich panel with the functionally graded faces.

thickness according to the volume fractions of the constituents. The core layer is constituted by the metal isotropic homogeneous material. The vertical positions of the bottom and top faces, and of two interfaces between the layers are respectively denoted by $h_{0}=-h / 2, h_{1}, h_{2}, h_{3}=h / 2$, which are directly related to $e_{c}, e_{f b}, e_{f t}$ being the thicknesses of the core, of the bottom and top faces respectively.

The distribution of elastic properties through the thickness of the sandwich plate is assumed by a power-law relation:

$E^{(k)}(z)=\left(E_{m}-E_{c}\right) V_{m}^{(k)}(z)+E_{c}$,

where $E_{c}$ and $E_{m}$ are the Young's moduli of ceramic and metal, $V_{m}{ }^{(k)}$ being given by:

$\left\{\begin{array}{lll}V_{m}^{(1)}(z)=\left(\frac{z-h_{0}}{h_{1}-h_{0}}\right)^{p} & \text { for } & z \in\left[h_{0}, h_{1}\right] \\ V_{m}^{(2)}(z)=1 & \text { for } & z \in\left[h_{1}, h_{2}\right] \\ V_{m}^{(3)}(z)=\left(\frac{z-h_{3}}{h_{2}-h_{3}}\right)^{p} & \text { for } & z \in\left[h_{2}, h_{3}\right]\end{array}\right.$

where $p$ is a material parameter which is positive, $h$ is the thickness of the plate and $z \in[-h / 2, h / 2]$. The implicit assumption within (19) is that the mixture of the two materials is taken into account by the "Voigt model". It can be shown that this assumption is convenient if the contrast between the phases is not too large. Many more approxima-

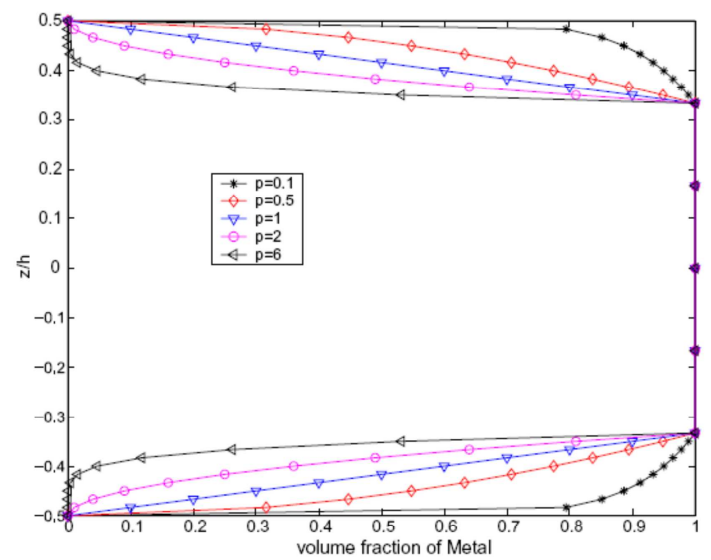

Fig. 3. Variation of $V_{m}$ through the thickness of the plate according to $p$. 


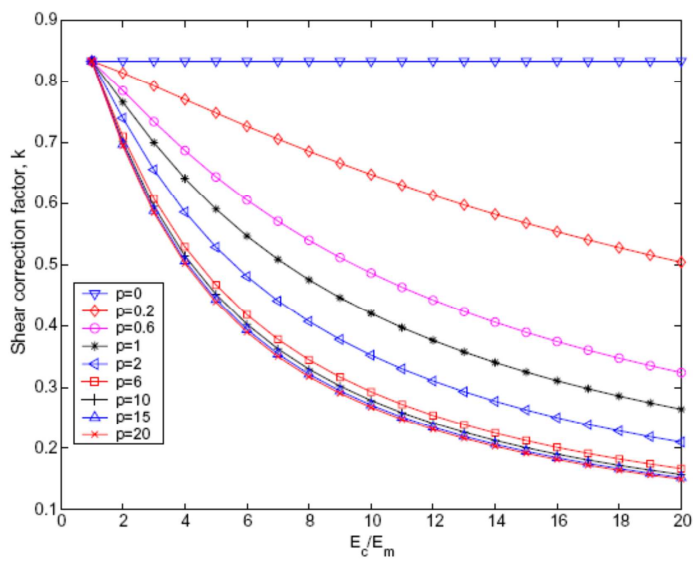

Fig. 4. Variation of the shear factors according to the ratio of $E_{c} / E_{m}$, $e_{c} / e_{f t}=4$.

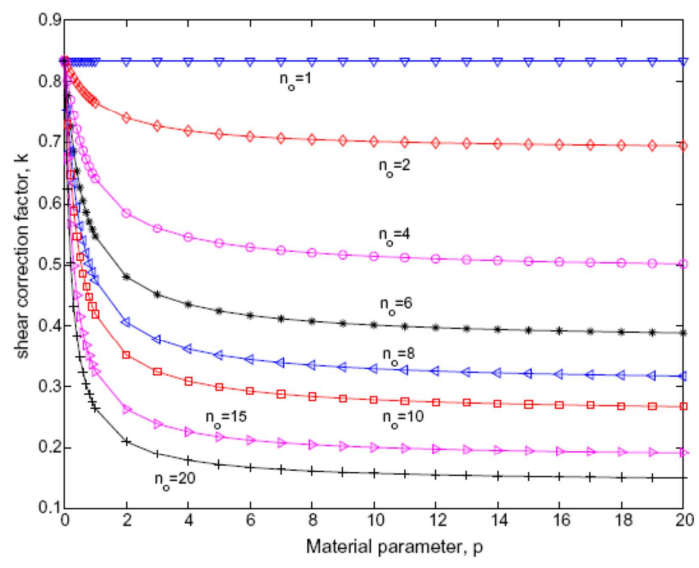

Fig. 5. Variation of the shear factor according to $p, e_{c} / e_{f t}=4$. tions of the effective elastic properties can be found within the literature $[8,31,39]$. The material variation profiles under consideration are shown in Fig. 3 for different values of $p$.

\subsubsection{Numerical results}

A sandwich panel that is clamped at two opposite ends and subjected to the uniformly distributed load acting downward $q_{0}$ (Fig. 2) is now considered. The closed-form expression of the displacement field within a FG sandwich panel is given in appendix. In this section, the effect on the deflection of the plate due to changing the shear correction factors is shown. In the following, the Poisson's ratio is assumed to be constant. The study of its effect on the static response of the plate can be found in $[5,6,30]$. The following parameters are used for numerical computations, $v=0.3, q_{0}=10^{4}, e_{f t}=0.01, e_{f b}=0.01$.

Figs. 4 and 5 present the variation profile of the shear correction factors according to the ratio of elastic moduli $n_{0}=E_{c} / E_{m}$ and to the power-law parameter $p$, where $p$ is within the range [0-20], while $n_{0}$ is within the range [120]. The ratio $e_{c} / e_{f t}$ is within the range $[1-40]$. The values of the shear correction factors for every couple $\left(p, n_{0}\right)$ and $\left(p, e_{c} / e_{f t}\right)$ are given in Tables 1 and 2 . It is important to notice that the shear correction factor $k$ depends strongly on the values of $p$ and on the ratio of $E_{c} / E_{m}$ and $e_{c} / e_{f t}$. It can be seen that the shear correction factors decrease when the ratio of the elastic moduli increases (Figs. 4 and 5). On the other hand, the shear correction factor increases when the ratio of thickness between the core and face increases (Fig. 6). The shear correction factor is equal to $5 / 6$ as for a homogeneous plate for $p=0$ and $n_{0}=1$ and is smaller than $5 / 6$ in other cases.

Table 2 and Fig. 6 represent the variation of the shear correction factor in terms of the ratio of the thickness of the homogeneous core and of the thickness of the functionally graded faces. When the ratio $e_{c} / e_{f t}$ is very large, the shear factor tends to the value obtained for homogenous plates (Fig. 6).

To consider the effect on the deflection of the sandwich panel induced by changing the shear correction factor, the

Table 1

Shear correction factors, $e_{c} / e_{f t}=4$

\begin{tabular}{|c|c|c|c|c|c|c|c|c|c|c|}
\hline$p$ & $E_{c} / E_{m}$ & & & & & & & & & \\
\hline & 1 & 2 & 3 & 4 & 5 & 6 & 8 & 10 & 15 & 20 \\
\hline 0 & $5 / 6$ & $5 / 6$ & $5 / 6$ & $5 / 6$ & $5 / 6$ & $5 / 6$ & $5 / 6$ & $5 / 6$ & $5 / 6$ & $5 / 6$ \\
\hline 0.2 & $5 / 6$ & 0.8137 & 0.7921 & 0.7699 & 0.7478 & 0.7262 & 0.6851 & 0.6474 & 0.5672 & 0.5037 \\
\hline 0.4 & $5 / 6$ & 0.7973 & 0.7589 & 0.7214 & 0.6860 & 0.6532 & 0.5949 & 0.5454 & 0.4505 & 0.3832 \\
\hline 0.6 & $5 / 6$ & 0.7843 & 0.7338 & 0.6865 & 0.6437 & 0.6051 & 0.5393 & 0.4859 & 0.3887 & 0.3237 \\
\hline 1.0 & $5 / 6$ & 0.7654 & 0.6993 & 0.6409 & 0.5902 & 0.5464 & 0.4749 & 0.4196 & 0.3245 & 0.2645 \\
\hline 2.0 & $5 / 6$ & 0.7395 & 0.6552 & 0.5855 & 0.5281 & 0.4805 & 0.4065 & 0.3520 & 0.2633 & 0.2102 \\
\hline 4.0 & $5 / 6$ & 0.7184 & 0.6215 & 0.5450 & 0.4843 & 0.4353 & 0.3616 & 0.3080 & 0.2263 & 0.1784 \\
\hline 6.0 & $5 / 6$ & 0.7093 & 0.6074 & 0.5284 & 0.4667 & 0.4175 & 0.3443 & 0.2926 & 0.2126 & 0.1669 \\
\hline 8.0 & $5 / 6$ & 0.7043 & 0.5996 & 0.5194 & 0.4572 & 0.4078 & 0.3350 & 0.2840 & 0.2055 & 0.1609 \\
\hline 10.0 & $5 / 6$ & 0.7011 & 0.5947 & 0.5137 & 0.4512 & 0.4018 & 0.3292 & 0.2786 & 0.2011 & 0.1572 \\
\hline 15.0 & $5 / 6$ & 0.6966 & 0.5877 & 0.5057 & 0.4428 & 0.3934 & 0.3212 & 0.2712 & 0.1950 & 0.1522 \\
\hline 20.0 & $5 / 6$ & 0.6942 & 0.5840 & 0.5014 & 0.4384 & 0.3890 & 0.3171 & 0.2674 & 0.1919 & 0.1496 \\
\hline
\end{tabular}


Table 2

Shear correction factors, $E_{c} / E_{m}=6$

\begin{tabular}{rccccccccrrr}
\hline$p$ & \multicolumn{10}{c}{$e_{c} / e_{f t}$} \\
\hline & 1 & 2 & 4 & 6 & 8 & 10 & 15 & 20 & 30 \\
0 & $5 / 6$ & $5 / 6$ & $5 / 6$ & $5 / 6$ & $5 / 6$ & $5 / 6$ & $5 / 6$ & $5 / 6$ & $5 / 6$ & $5 / 6$ \\
1 & 0.4591 & 0.4819 & 0.5464 & 0.5990 & 0.6392 & 0.6701 & 0.7215 & 0.7520 & 0.7848 & 0.8012 \\
2 & 0.3981 & 0.4158 & 0.4805 & 0.5368 & 0.5815 & 0.6171 & 0.6790 & 0.7177 & 0.7615 & 0.7844 \\
4 & 0.3583 & 0.3719 & 0.4353 & 0.4929 & 0.5399 & 0.5780 & 0.6462 & 0.6903 & 0.7420 & 0.7700 \\
6 & 0.3429 & $\mathbf{0 . 3 5 4 7}$ & 0.4175 & 0.4754 & 0.5231 & 0.5620 & 0.6326 & 0.6787 & 0.7335 & 0.7635 \\
8 & 0.3347 & 0.3454 & 0.4078 & 0.4659 & 0.5139 & 0.5533 & 0.6250 & 0.6723 & 0.7287 & 0.7599 \\
10 & 0.3294 & 0.3397 & 0.4018 & 0.4599 & 0.5081 & 0.5478 & 0.6203 & 0.6682 & 0.7257 & 0.7576 \\
\hline
\end{tabular}

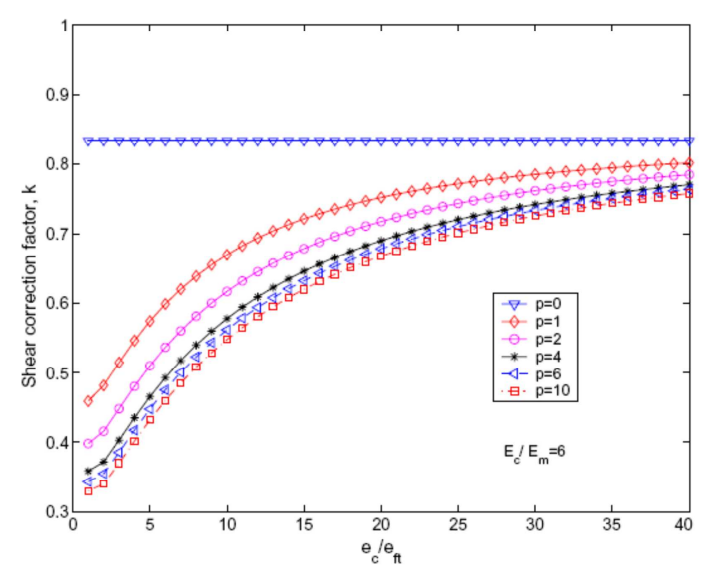

Fig. 6. Variation of the shear factors in terms of the ratio of $e_{c} / e_{f t}$, $E_{c} / E_{m}=6$.

value $k=0.3547$ is taken (Table 2). This value corresponds to $p=6, E_{c} / E_{m}=6\left(\mathrm{SiC}, E_{c}=420 \mathrm{GPa}\right.$ and aluminum, $\left.E_{m}=70 \mathrm{GPa}\right)$ and $e_{c} / e_{f t}=2$. The obtained deflection is

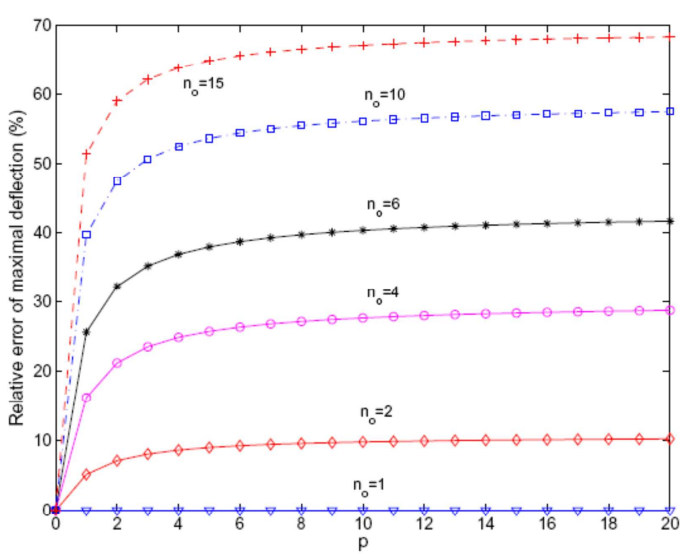

Fig. 7. Relative error of maximal deflection in terms of $p, e_{c} / e_{f t}=2, a$ / $h=5$. compared in a first step to that of the model using the correction factor $k=5 / 6$. The measurement of a "relative error"' is defined by the relationship:

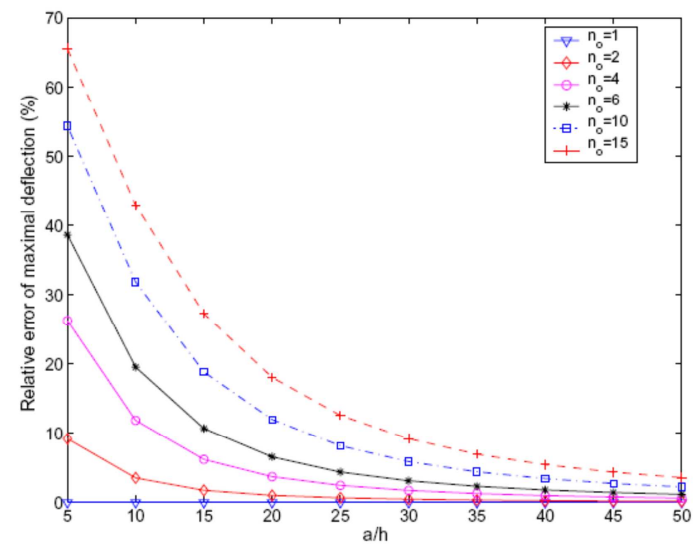

Fig. 8. Relative error of maximal deflection according to the ratio of length-thickness, $e_{c} / e_{f t}=2, p=6$.

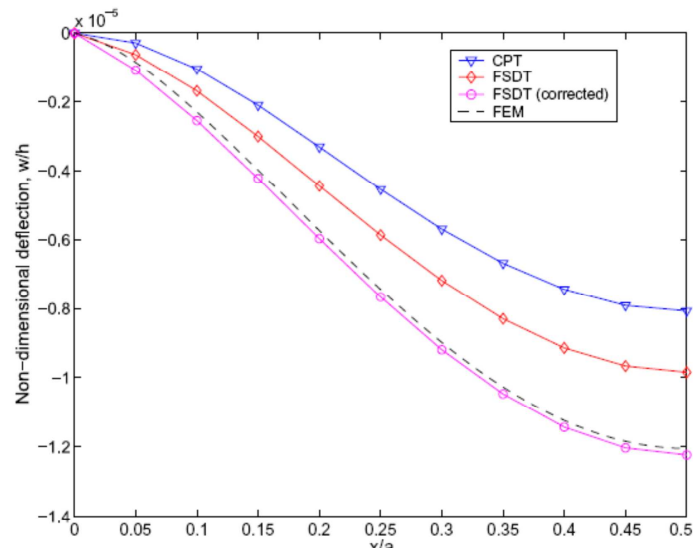

Fig. 9. Variation profile of deflection for various model, $E_{c} / E_{m}=6, p=6$, $a / h=10, e_{c} / e_{f t}=2$ 
Table 3

Deflection and relative error in a clamped sandwich strip, $E_{c} / E_{m}=6, p=6, e_{c} / e_{f t}=2$

\begin{tabular}{lllll}
\hline$a / h$ & FEM & FSDT & & $k=5 / 6$ \\
\cline { 3 - 5 } & & $k=1$ & $3.791 \mathrm{e}-8(-37.06 \%)$ & $k=0.3547$ \\
\hline 5 & $6.023 \mathrm{e}-8$ & $3.495 \mathrm{e}-08(-41.97 \%)$ & $3.938 \mathrm{e}-7(-18.33 \%)$ & $6.183 \mathrm{e}-8(2.66 \%)$ \\
10 & $4.822 \mathrm{e}-7$ & $3.820 \mathrm{e}-07(-20.78 \%)$ & $5.450 \mathrm{e}-6(-7.12 \%)$ & $4.895 \mathrm{e}-7(1.51 \%)$ \\
20 & $5.868 \mathrm{e}-6$ & $5.403 \mathrm{e}-06(-7.92 \%)$ & $2.679 \mathrm{e}-5(-4.12 \%)$ & $5.833 \mathrm{e}-6(-0.60 \%)$ \\
30 & $2.794 \mathrm{e}-5$ & $2.669 \mathrm{e}-05(-4.47 \%)$ & $8.379 \mathrm{e}-5(-2.98 \%)$ & $2.765 \mathrm{e}-5(-1.04 \%)$ \\
40 & $8.636 \mathrm{e}-5$ & $8.360 \mathrm{e}-05(-3.20 \%)$ & $2.036 \mathrm{e}-4(-2.40 \%)$ & $8.532 \mathrm{e}-5(-1.20 \%)$ \\
50 & $2.086 \mathrm{e}-4$ & $2.033 \mathrm{e}-04(-2.54 \%)$ & & $2.060 \mathrm{e}-4(-1.25 \%)$ \\
\hline
\end{tabular}

error $(\%)=\frac{M_{c}-M_{m}}{M_{m}} \times 100 \%$

where $M_{m}$ is the value of the maximum deflection obtained from the present model, and $M_{c}$ is that of other models.

Figs. 7 and 8 show the variation profile of the relative error of the maximal deflection at the center of the plate for the corrected shear coefficient using the five-sixth factor. It can be observed that the difference increases with the value $n_{0}$ and the plate thickness. That is explained by the fact that the correction factor decreases strongly in those cases. The difference between the maximal deflection for the case of the five-sixth factor compared to the present model is $37.5 \%$ for $n_{0}=6(\mathrm{SiC}-\mathrm{Al})$ and $p=6$. This deviation is higher for a larger value of $n_{0}$.

The validation of the solution of the present model is performed by comparison with that of a finite element model. The finite element computation is performed with five discrete layers through the layer-thickness of the plate. The 3D solution is obtained by using Abaqus software and linear quadrilateral elements CPE4R (plane strain). In comparison, the deflection obtained by the finite element model is approximately equal to that of the model using the corrected shear factor (Fig. 9). The relative error in comparison with the finite element solution is determined by using (21) (where $M_{m}$ is the magnitude given by the

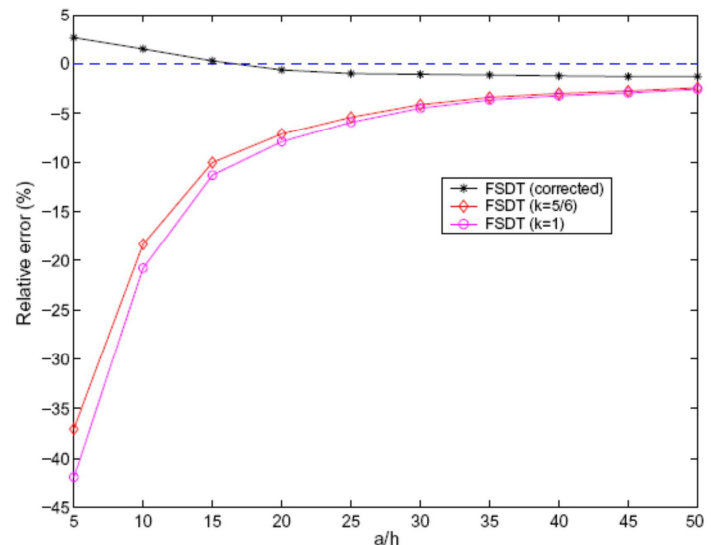

Fig. 10. Relative error of the maximal deflection, $E_{c} / E_{m}=6, p=6$, $e_{c} / e_{f t}=2$. discrete finite element model, and $M_{c}$ that of the other models). The errors can be seen in Table 3 and are shown in Fig. 10. It is seen that the corrected FSDT solution is in a good agreement with the finite element solution, whereas the results obtained by the FSDT model taking the factor of correction $k=5 / 6$ are different even for a thin plate.

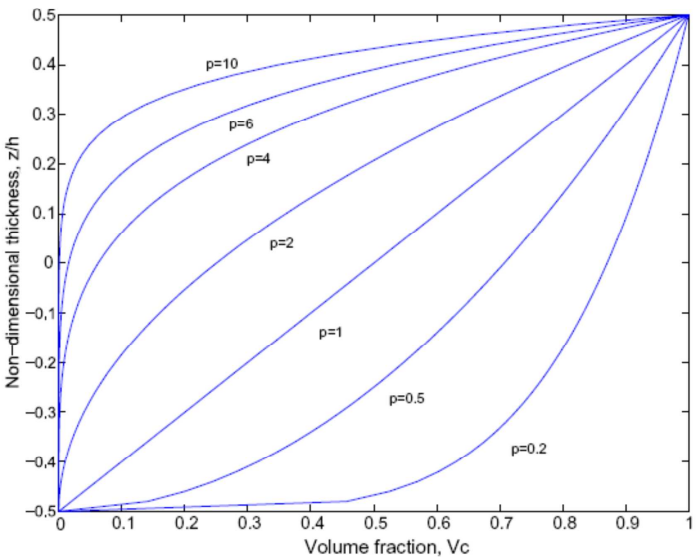

Fig. 11. Variation of $V_{c}$ through plate thickness for various values of $p$.

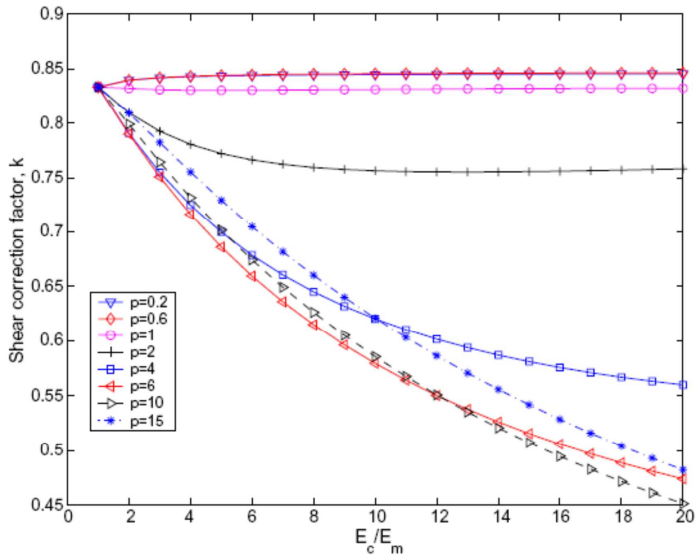

Fig. 12. Variation of the shear correction factor according to $n_{0}=E_{c} / E_{m}$. 


\subsection{Functionally graded simply supported plate}

\subsubsection{Material distribution}

The distribution of a functionally graded material within a non-symmetrical plate is now considered. The plate is made of a mixture of ceramic and metallic components (Fig. 1).

The effective modulus through the plate is defined in (19) where $V_{m}(z)=1-V_{c}(z)$.

$V_{c}(z)=\left(\frac{z+\frac{h}{2}}{h}\right)^{p}$.

The distribution of the materials under consideration (22) is presented in Fig. 11. It can be seen that the $V_{c}$ varies quickly near the lowest surface for $p<1$ and increases quickly near the top surface for $p>1$.

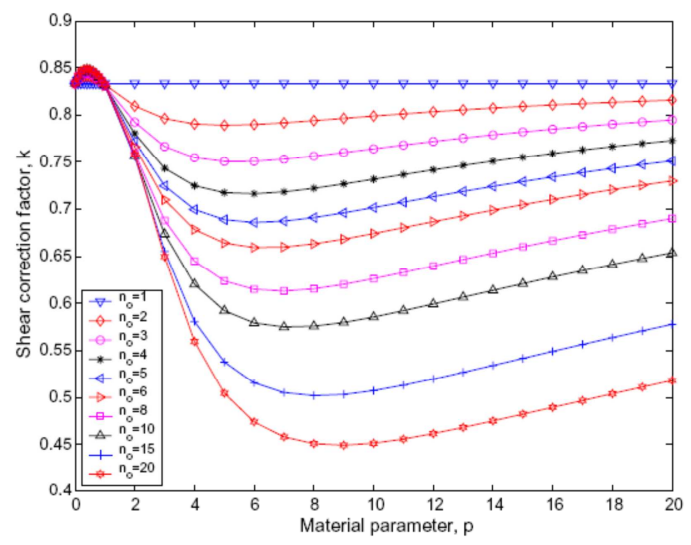

Fig. 13. Variation of the shear correction factor according to $p$.
3.2.2. Numerical results

In this part, the effect on the deflection of the plate due to changing the shear correction factors will be shown. Moreover, some results for the static analysis of a squared, simply supported FG plate under uniformly distributed load of intensity $q_{0}$, are presented. They are compared to the third-order shear deformation plate model (TSDT) of Reddy [22], the sinusoidal shear deformation plate model (SSDT) of Zenkour [33] and a discrete three-dimensional finite element model. The following parameters are used for numerical computations, $v=0.3, a=b=1, q_{0}=10^{4}$. The deflection and stress fields within the plate are obtained by the Navier's solution given in the appendix. The following non-dimensional parameters are used: $\bar{w}=w / h, \bar{\sigma}=\sigma h^{2} /\left(q_{0} a^{2}\right)$.

Figs. 12 and 13 present the variation of the shear correction factors according to $n_{0}$ and $p$, where the parameters $p$ and $n_{0}$ are changed as for the previously studied sandwich panel. The shear correction factors are equal to $5 / 6$ as for a homogeneous plate for $p=0$ or $n_{0}=1$ and approximately this usual value for $p=1$. They are higher than $5 / 6$ for $p<1$.

Table 4 gives the values of shear correction factors related to every couple $\left(p, n_{0}\right)$. It can be seen that, with the same material distribution of FGM ( $\mathrm{SiC}-\mathrm{Al})$, the shear factor of the plate $(k=0.6595)$ is larger than for the case of a symmetric sandwich plate $(k=0.3547$, see Table 2$)$.

The relative error is obtained by formula (21) where $M_{m}$ is the magnitude obtained by the corrected FSDT model and $M_{c}$ the value taken from FSDT model. Fig. 14 presents the variation of the relative error on the maximal deflection in terms of the parameters $\left(p, n_{0}\right)$. This difference is shown in Fig. 15 as a function of the ratio length-thickness of the plate. It can be seen in this case that the variation of the shear correction factor does not affect the deflection of the thin and medium-thick plates. This is due to the fact

Table 4

Shear correction factors for the FG plate

\begin{tabular}{|c|c|c|c|c|c|c|c|c|c|c|}
\hline$p$ & $E_{c} / E_{m}$ & & & & & & & & & \\
\hline & 1 & 2 & 3 & 4 & 5 & 6 & 8 & 10 & 15 & 20 \\
\hline 0 & $5 / 6$ & $5 / 6$ & $5 / 6$ & $5 / 6$ & $5 / 6$ & $5 / 6$ & $5 / 6$ & $5 / 6$ & $5 / 6$ & $5 / 6$ \\
\hline 0.2 & $5 / 6$ & 0.8396 & 0.8418 & 0.8429 & 0.8435 & 0.8440 & 0.8445 & 0.8448 & 0.8453 & 0.8455 \\
\hline 0.4 & $5 / 6$ & 0.8411 & 0.8439 & 0.8453 & 0.8462 & 0.8467 & 0.8474 & 0.8478 & 0.8483 & 0.8486 \\
\hline 0.6 & $5 / 6$ & 0.8396 & 0.8420 & 0.8433 & 0.8441 & 0.8446 & 0.8453 & 0.8457 & 0.8461 & 0.8463 \\
\hline 0.8 & $5 / 6$ & 0.8364 & 0.8374 & 0.8381 & 0.8386 & 0.8389 & 0.8395 & 0.8399 & 0.8404 & 0.8406 \\
\hline 1.0 & $5 / 6$ & 0.8320 & 0.8309 & 0.8305 & 0.8304 & 0.8305 & 0.8308 & 0.8312 & 0.8319 & 0.8323 \\
\hline 2.0 & $5 / 6$ & 0.8095 & 0.7924 & 0.7804 & 0.7720 & 0.7662 & 0.7593 & 0.7563 & 0.7555 & 0.7580 \\
\hline 3.0 & $5 / 6$ & 0.7961 & 0.7666 & 0.7433 & 0.7247 & 0.7099 & 0.6882 & 0.6738 & 0.6556 & 0.6498 \\
\hline 4.0 & $5 / 6$ & 0.7905 & 0.7547 & 0.7248 & 0.6997 & 0.6786 & 0.6451 & 0.6203 & 0.5810 & 0.5599 \\
\hline 5.0 & $5 / 6$ & 0.7891 & 0.7506 & 0.7175 & 0.6890 & 0.6643 & 0.6238 & 0.5923 & 0.5381 & 0.5046 \\
\hline 6.0 & $5 / 6$ & 0.7899 & 0.7507 & 0.7163 & 0.6861 & 0.6595 & 0.6150 & 0.5794 & 0.5158 & 0.4741 \\
\hline 7.0 & $5 / 6$ & 0.7917 & 0.7530 & 0.7183 & 0.6875 & 0.6600 & 0.6132 & 0.5751 & 0.5053 & 0.4581 \\
\hline 8.0 & $5 / 6$ & 0.7940 & 0.7563 & 0.7221 & 0.6912 & 0.6634 & 0.6155 & 0.5759 & 0.5020 & 0.4508 \\
\hline 9.0 & $5 / 6$ & 0.7964 & 0.7602 & 0.7267 & 0.6962 & 0.6685 & 0.6202 & 0.5799 & 0.5032 & 0.4492 \\
\hline 10.0 & $5 / 6$ & 0.7989 & 0.7642 & 0.7316 & 0.7017 & 0.6743 & 0.6262 & 0.5856 & 0.5073 & 0.4513 \\
\hline 15.0 & $5 / 6$ & 0.8090 & 0.7820 & 0.7551 & 0.7293 & 0.7048 & 0.6602 & 0.6210 & 0.5419 & 0.4823 \\
\hline 20.0 & $5 / 6$ & 0.8157 & 0.7947 & 0.7729 & 0.7511 & 0.7300 & 0.6902 & 0.6540 & 0.5780 & 0.5183 \\
\hline
\end{tabular}




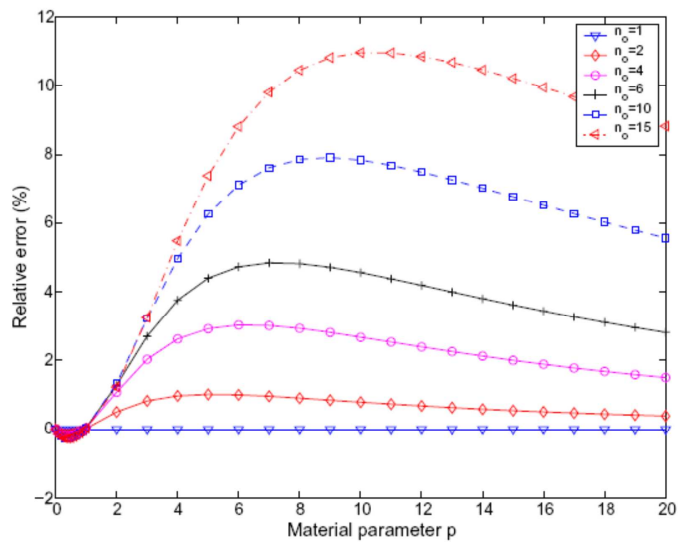

Fig. 14. Relative error of maximal deflection, $a / h=5$.

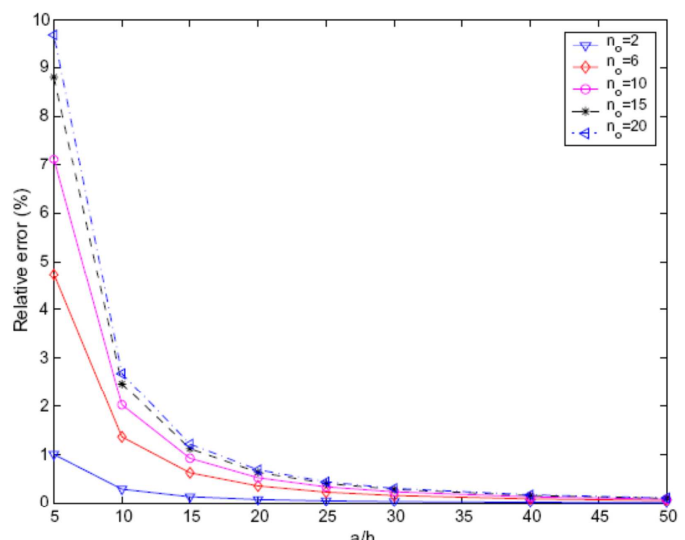

Fig. 15. Relative error of maximal deflection, $p=6$.

that the contribution of the shear deformation energy is negligible compared to the bending deformation energy. The effect of the shear correction factor is non-negligible only for the thick plate $(a / h \leqslant 10)$. However, the effect of the shear correction factor becomes more significant when the ratio of elastic moduli increases (see Fig. 15).

In order to validate the results of the model, a comparison is made with previous results of the literature and with a finite element solution. To do this, a three-dimensional finite element computation with element C3D8R is performed as explained in the previous section. An appropriate meshing comprising 8 discrete layers in the thickness direction is used.

It can be seen in Fig. 16 that the deflection obtained from the present study is identical to that of the discrete three-dimensional finite element model and to the higherorder shear deformation models (TSDT, SSDT). The difference between these results and the result received from the model using the five-sixth shear correction factor is

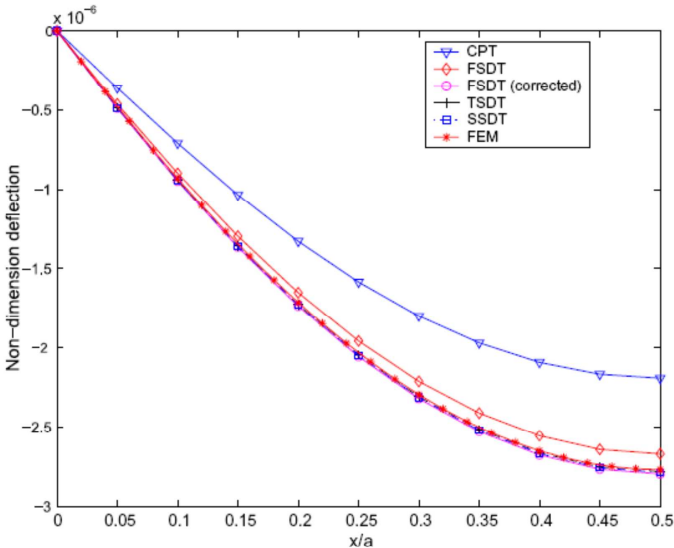

Fig. 16. Non-dimensional deflection for various models, $a / h=5, p=6$, $\mathrm{SiC}-\mathrm{Al}$.

approximately $5 \%$ for the $\mathrm{SiC}-\mathrm{Al} \mathrm{FGM}, 7 \%$ for $\mathrm{WC}-\mathrm{Al}$ FGM and this percentage continue to increase in terms of the augmentation of $n_{0}$. Furthermore, the models taking into accounts the shear deformation are also compared to the model of Love-Kirchhoff in Fig. 16. That comparison allows us to remark that there is an important difference between the CPT model and the others. That is logical because the contribution of shear deformation energy is significant for the actual thickness of plate $(a / h=5)$.

The variation of the plane stress $\sigma_{x x}$ at the center of the FG plate along the thickness direction is depicted in Fig. 17. It can be seen that the maximum compressive stress is at the top surface and increases with $p$. In comparison, the maximum tensile stress is located inside the plate for $p<1$. This is a significant difference compared with usual homogeneous composite laminate. There is not important difference of the membrane stresses between the models, the prediction of the their distribution is thus not represented.

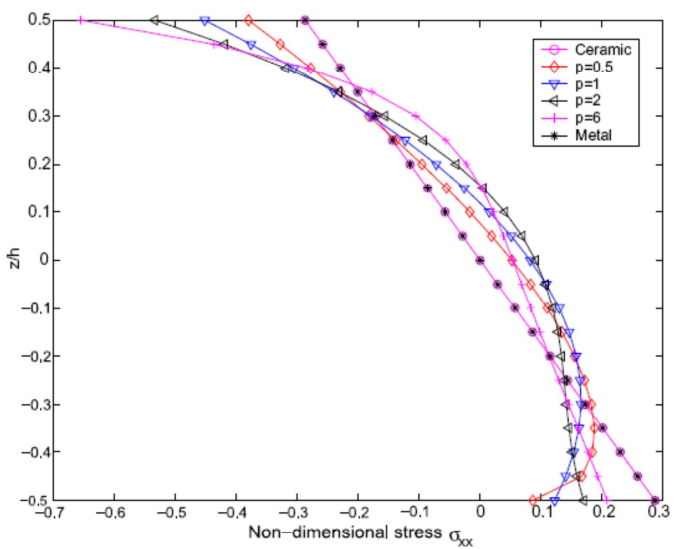

Fig. 17. Non-dimensional stress $\bar{\sigma}_{x x}, a / h=5, \mathrm{Si}-\mathrm{Al}$. 
The transverse shear stress defined in (13) near the boundary edge $(x=99 a / 100, y=49 b / 100)$ is shown in Figs. 18-20. It is compared to the shear stress given by higher-order models and to the results obtained from a three-dimensional finite element model. In comparison, the shear stresses of the corrected FSDT model and those of the three-dimensional element finite model are nearly the same. It can be seen that, for higher-order models, the curves are clearly different for the three models (FSDT, TSDT, SSDT) (see Figs. 19 and 20). The relative difference between the values of shear stresses can reach 25\% (Fig. 20) at some locations within the plate for $\left(n_{0}=6, p=6\right)$. Clearly, this distinction depends on the parameters $n_{0}$ and $p$. The difference between the FSDT model and the higher-order models (TSDT, SSDT) is indeed small for the smaller values of $\left(n_{0, p}\right)$ (see Fig. 18).

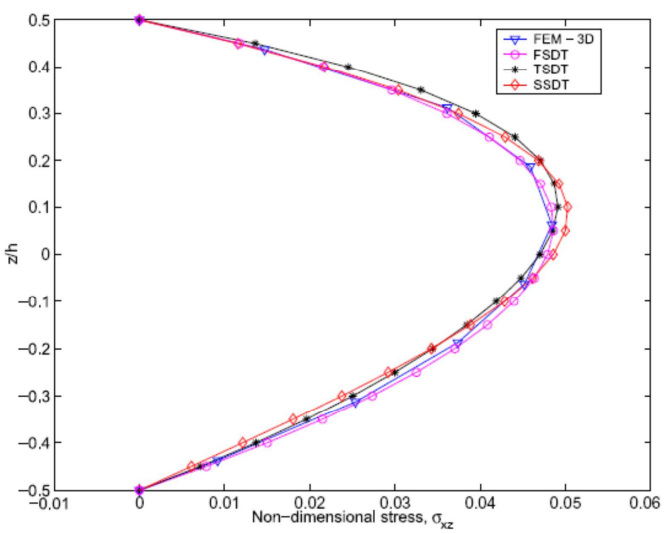

Fig. 18. Non-dimensional stress $\bar{\sigma}_{x z}, E_{c} / E_{m}=2, p=2, a / h=10$.

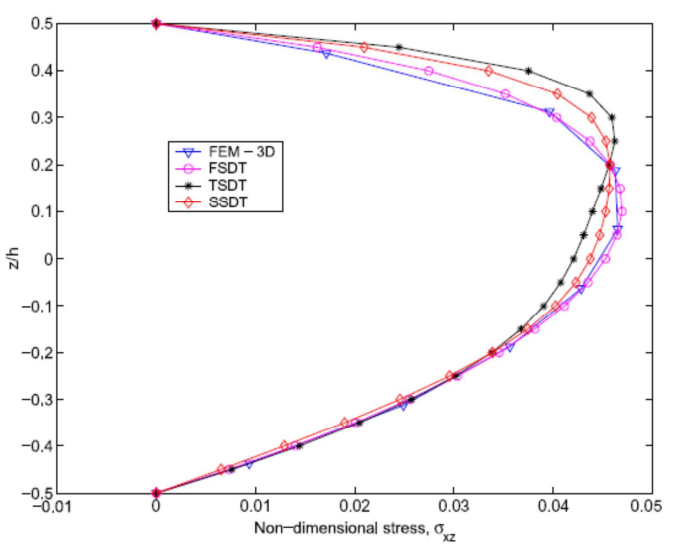

Fig. 19. Non-dimensional stress $\bar{\sigma}_{x z}, E_{c} / E_{m}=4, p=6, a / h=10$.

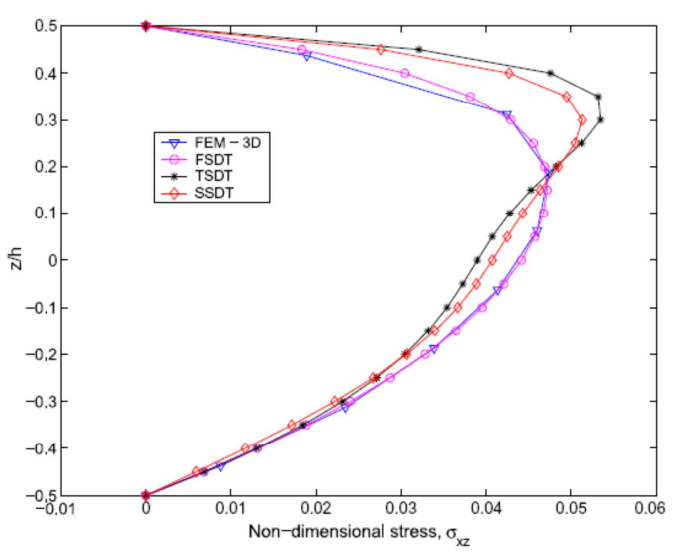

Fig. 20. Non-dimensional stress $\bar{\sigma}_{x z}, E_{c} / E_{m}=6, p=6, a / h=10$.

\section{Conclusions}

The improved shear stiffnesses and shear correction coefficients for the functionally graded plate models using FSDT were presented. The closed-form solutions for the simply supported square functionally graded plate and for the cylindrical bended sandwich plate with functionally graded faces based on the first-order shear deformation (FSDT) were obtained. The obtained results show that the shear correction factor is not the same as the one of the homogeneous FSDT models, and is a function of the ratio between elastic moduli of constituents and of the distribution of materials through the models. Its effect is the most significant for the sandwich plate. For a classical, non-symmetrical FGM plate, the maximum tensile stress is located within the plate, contrarily to the case of a homogenous plate. The variation of the shear stress through the thickness of the FG plate given by the FSDT model is identical to the one given by the finite element model.

Appendix A. Navier's solution for the functionally graded Reissner-Mindlin plate

The boundary conditions for the simply supported rectangular plates are of the form,

$$
\begin{array}{lll}
u_{0}(x, 0)=0, & w_{0}(x, 0)=0, & \theta_{x}(x, 0)=0, \\
u_{0}(x, b)=0, & w_{0}(x, b)=0, & \theta_{x}(x, b)=0, \\
v_{0}(0, y)=0, & w_{0}(0, y)=0, & \theta_{y}(0, y)=0, \\
v_{0}(a, y)=0, & w_{0}(a, y)=0, & \theta_{y}(a, y)=0, \\
N_{x x}(0, y)=0, & N_{x x}(a, y)=0, \\
N_{y y}(x, 0)=0, & N_{y y}(x, b)=0,
\end{array}
$$$$
M_{x x}(0, y)=0, \quad M_{x x}(a, y)=0
$$$$
M_{y y}(x, 0)=0, \quad M_{y y}(x, b)=0 .
$$ 
The external force is expressed as a double trigonometric series,

$q(x, y)=\sum_{n=1}^{\infty} \sum_{m=1}^{\infty} q_{m n} \sin \lambda x \sin \mu y$,

where $\lambda=m \pi / a$ and $\mu=n \pi / b$. The coefficients $q_{m n}$ for the uniformly distributed load are defined as follows:

$q_{m n}= \begin{cases}\frac{16 q_{0}}{m n^{2}} & \text { for } m, n \text { odd } \\ 0 & \text { for } m, n \text { even }\end{cases}$

where $q_{0}$ represents the load intensity on the plate surface. The Navier's solution for simply supported plates under the uniform distributed load is given by:

$u_{0}(x, y)=\sum_{n=1}^{\infty} \sum_{m=1}^{\infty} u_{m n} \cos \lambda x \sin \mu y$,

$v_{0}(x, y)=\sum_{n=1}^{\infty} \sum_{m=1}^{\infty} v_{m n} \sin \lambda x \cos \mu y$,

$w_{0}(x, y)=\sum_{n=1}^{\infty} \sum_{m=1}^{\infty} w_{m n} \sin \lambda x \sin \mu y$

$\theta_{x}(x, y)=\sum_{n=1}^{\infty} \sum_{m=1}^{\infty} x_{m n} \cos \lambda x \sin \mu y$,

$\theta_{y}(x, y)=\sum_{n=1}^{\infty} \sum_{m=1}^{\infty} y_{m n} \sin \lambda x \cos \mu y$.

The equilibrium equations of plates are given by,

$N_{\alpha \beta, \beta}=0, \quad M_{\alpha \beta \beta \beta}=Q_{\alpha}, \quad Q_{\alpha, \alpha}+q=0$.

The constitutive relations can be written as:

$N_{\alpha \beta}(x, y)=A_{\alpha \beta \gamma \delta} \epsilon_{\gamma \delta}^{0}(x, y)+B_{\alpha \beta \gamma \delta} \chi_{\gamma \delta}(x, y)$,

$M_{\alpha \beta}(x, y)=B_{\alpha \beta \gamma \delta} \epsilon_{\gamma \delta}^{0}(x, y)+D_{\alpha \beta \gamma \delta} \chi_{\gamma \delta}(x, y)$,

$Q_{\alpha}(x, y)=H_{\alpha \beta} \gamma_{\beta 3}(x, y)$ given in (14),

where $\epsilon_{\gamma \delta}^{0}$ and $\chi_{\gamma \delta}$ are given in (2), and $H_{\alpha \beta}$ are the improved shear stiffnesses given in (17). Substituting Eqs. $26,27,28,29,30,(24)$ and (25) into (31), the following equation system is obtained,

$\left[\begin{array}{ccccc}s_{11} & s_{12} & 0 & s_{14} & s_{15} \\ s_{12} & s_{22} & 0 & s_{24} & s_{25} \\ 0 & 0 & s_{33} & s_{34} & s_{35} \\ s_{14} & s_{24} & s_{34} & s_{44} & s_{45} \\ s_{15} & s_{25} & s_{35} & s_{45} & s_{55}\end{array}\right]\left\{\begin{array}{c}u_{m n} \\ v_{m n} \\ w_{m n} \\ x_{m n} \\ y_{m n}\end{array}\right\}=\left\{\begin{array}{c}0 \\ 0 \\ q_{m n} \\ 0 \\ 0\end{array}\right\}$,

where the coefficients of the matrix $s$ are given by,

$$
\begin{array}{ll}
s_{11}=A_{1111} \lambda^{2}+A_{1212} \mu^{2}, & s_{12}=\left(A_{1122}+A_{1212}\right) \lambda \mu, \\
s_{14}=B_{1111} \lambda^{2}+B_{1212} \mu^{2}, & s_{15}=\left(B_{1122}+B_{1212}\right) \lambda \mu, \\
s_{22}=A_{1212} \lambda^{2}+A_{2222} \mu^{2}, & s_{24}=s_{15}, \\
s_{25}=B_{1212} \lambda^{2}+B_{2222} \mu^{2}, & s_{33}=H_{55} \lambda^{2}+H_{44} \mu^{2},
\end{array}
$$

$$
\begin{aligned}
& s_{34}=H_{55} \lambda, s_{35}=H_{44} \mu, \\
& s_{44}=H_{55}+D_{1111} \lambda^{2}+D_{1212} \mu^{2}, \\
& s_{45}=\left(D_{1122}+D_{1212}\right) \lambda \mu, \\
& s_{55}=H_{44}+D_{2222} \mu^{2}+D_{1212} \lambda^{2}
\end{aligned}
$$

The in-plane stress fields are defined as follows,

$$
\begin{aligned}
\sigma_{x x}= & -\frac{E(z)}{1-v(z)^{2}} \sum_{n=1}^{\infty} \sum_{m=1}^{\infty}\left[\left(u_{m n} \lambda+v(z) \mu v_{m n}\right)\right. \\
& \left.+z\left(x_{m n} \lambda+v(z) \mu y_{m n}\right)\right] \sin \lambda x \sin \mu y \\
\sigma_{y y}= & -\frac{E(z)}{1-v(z)^{2}} \sum_{n=1}^{\infty} \sum_{m=1}^{\infty}\left[\left(v_{m n} \mu+v(z) \lambda u_{m n}\right)\right. \\
& \left.+z\left(y_{m n} \mu+v(z) \lambda x_{m n}\right)\right] \sin \lambda x \sin \mu y \\
\sigma_{x y}= & \frac{E(z)}{2(1+v(z))} \sum_{n=1}^{\infty} \sum_{m=1}^{\infty}\left[\left(u_{m n} \mu+\lambda v_{m n}\right)\right. \\
& \left.+z\left(x_{m n} \mu+\lambda y_{m n}\right)\right] \cos \lambda x \cos \mu y
\end{aligned}
$$

Transverse shear stresses are determined by expression (13) as follows,

$\sigma_{x z}=\tilde{m}_{1111}(z) H_{55} \sum_{n=1}^{\infty} \sum_{m=1}^{\infty}\left[x_{m n}+\lambda w_{m n}\right] \cos \lambda x \sin \mu y$,
$\sigma_{y z}=\tilde{m}_{1212}(z) H_{44} \sum_{n=1}^{\infty} \sum_{m=1}^{\infty}\left[y_{m n}+\mu w_{m n}\right] \sin \lambda x \cos \mu y$.

\section{Appendix B. Closed-form solution for the functionally} graded sandwich panel in cylindrical bending

Assuming that for cylindrical bending $\theta_{y}=0$ everywhere, the boundary conditions for the clamped sandwich panel are of the form,

$$
\begin{aligned}
& v_{0}(x=0)=0, u_{0}(x=0), w(x=0)=0, \\
& \theta_{x}(x=0)=0, \\
& v_{0}(x=a)=0, u_{0}(x=a)=0, w(x=a)=0, \\
& \theta_{x}(x=a)=0 .
\end{aligned}
$$

The equilibrium Eq. (31) for the cylindrical bending plate can be written simplify as follows,

$M_{x x, x}-Q_{x}=0, Q_{x, x}+q=0, N_{x x, x}=0$.

The generalized constitutive relations (32) for the isotropic materials are expressed explicitly,

$\left\{\begin{array}{l}N_{x x}=A_{1111} u_{0, x}+B_{1111} \theta_{x, x}, \\ N_{y y}=A_{1122} u_{0, x}+B_{1122} \theta_{x, x}, \\ N_{x y}=A_{1212} v_{0, x} .\end{array}\right.$

$\left\{\begin{array}{l}M_{x x}=B_{1111} u_{0, x}+D_{1111} \theta_{x, x}, \\ M_{y y}=B_{1122} u_{0, x}+D_{1122} \theta_{x, x}, \\ M_{x y}=B_{1212} v_{0, x}\end{array}\right.$

and

$Q_{x}=H_{55}\left(\theta_{x}+w_{, x}\right)$. 
Similarly, substituting the expressions (42)-(44) into the equilibrium Eq. (41), leads to the following relations:

$D \theta_{x, x}-H_{55}\left(\theta_{x}+w_{, x}\right)=0$,

$H_{55}\left(w_{0, x x}+\theta_{x, x}\right)+q=0$,

where $D=D_{1111}-B_{1111}^{2} / A_{1111}$ is the stiffness of the sandwich panel. For $q(x)=q_{0}=$ const and by applying the boundary conditions (40), the Eqs. (45) and (46) lead to:

$\theta_{x}(x)=-\frac{q_{0} a^{3}}{12 D}\left[2\left(\frac{x}{a}\right)^{3}-3\left(\frac{x}{a}\right)^{2}+\left(\frac{x}{a}\right)\right]$

$w_{0}(x)=\frac{q_{0} a^{4}}{24 D}\left[\left(\frac{x}{a}\right)^{2}-\left(\frac{x}{a}\right)\right]^{2}+\frac{q_{0} a^{2}}{2 H_{55}}\left[\left(\frac{x}{a}\right)-\left(\frac{x}{a}\right)^{2}\right]$.

The maximal deflection obtained at the middle of the plate $(x=a / 2)$ is of the form:

$w_{0 \max }=\frac{q_{0} a^{4}}{384 D}\left(1+\frac{48 D}{H_{55} a^{2}}\right)$

\section{References}

[1] Berthelot JM. Matériaux composites: Comportement mécanique et analyse des structures. Paris: Masson; 1992.

[2] Caron JF, Sab K. Un nouveau modèle de plaque multicouche épaisse. Acad Sci 2001;329:595-600.

[3] Cheng ZQ, Batra RC. Exact correspondence between eigenvalues of membranes and functionally graded simply supported polygonal plates. J Sound Vib 2000;229:879 95.

[4] Cheng ZQ, Batra RC. Three-dimensional thermoelastic deformations of functionally graded elliptic plates. J Sound Vib 2000;31:97-106.

[5] Chi S, Chung Y. Mechanical behavior of functionally graded material plates under transverse load - Part I: Analysis. Int J Solids Struct 2006:43:3657-74.

[6] Chi S, Chung Y. Mechanical behavior of functionally graded material plates under transverse load - Part II: Numerical results. Int J Solids Struct 2006:43:3675-91.

[7] Elishakoff I, Gentilini C, Viloa E. Three-dimensional analysis of an all-round clamped plate made of functionally graded materials. Acta Mech 2005;180:21-36.

[8] Gasik MM. Micromechanical modelling of functionally graded materials. Comput Mater Sci 1998:13:42-55.

[9] Ghugal YM, Shimpi RP. A review of refined shear deformation theories of isotropic and anisotropic laminated plates. J Reinforced Plast Compos 2002;21:775-813.

[10] Gruttmann F, Wagner W. Shear correction factors in Timoshenko's beam theory for arbitrary shaped cross-sections. Comput Mech 2001;27:199-207.

[11] Hutchinson JR. Shear coefficients for Timoshenko beam theory. J Appl Mech 2001;68:87-92.

12] He XQ, Ng TY, Sivashankera S, Liew KM. Active control of FGM plates with integrated piezoelectric sensors and actuators. Int J Solids Struct 2001;38:1641-55.

[13] Koizumi M. FGM Activities in Japan. Composites 1997;28:1-4.

[14] Lee K, Lee SW. A postprocessing approach to determine transverse stresses in geometrically nonlinear composite and sandwich structures. J Compos Mater 2003;37:2207-24.

[15] Croce LD, Venini P. Finite elements for functionally graded Reissner Mindlin plates. Comput Methods Appl Mech Eng 2004;193:705-25.
16] Mindlin RD. Influence of rotary inertia and shear on flexural motion of isotropic elastic plates. J Appl Mech 1951;18:31-8.

[17] Praveen GN, Reddy JN. Nonlinear transient thermoelastic analysis of functionally graded ceramic-metal plates. Int $\mathbf{J}$ Solids Struct 1998;35:4457-76.

[18] Ramirez F, Heyliger PR, Pan E. Static analysis of functionally graded elastic anisotropic plates using a discrete layer approach. Compos B Eng 2006;37:10-20.

[19] Reissner E. The effect of transverse shear deformation on the bending of elastic plates. J Appl Mech 1945;13:69-77.

[20] Reddy JN. Theory and analysis of elastic plates. Philadelphia: Taylor Francis; 1999.

[21] Reddy JN. Mechanics of laminated composites plates: Theory and analysis. Boca Raton: CRC Press; 1997.

[22] Reddy JN. Analysis of functionally graded materials. Int J Numer Methods Eng 2000;47:663-84

[23] Reddy JN. A new beam finite element for the analysis of functionally graded materials. Int J Mech Sci 2003;45:519-39.

[24] Rolfes R, Rohwer K, Ballerstaedt M. Efficient linear transverse normal stress analysis of layered composite plates. Comput Struct 1998;68:643-52.

[25] Rolfes R, Rohwer K. Improved transverse shear stresses in composite finite elements based on first order shear deformation theory. Int J Numer Methods Eng 1997;40:51-60.

[26] Satchi V, Bhavani V. Analysis of sandwich beams with functionally graded core. AIAA 2001;1:752-9.

27] Vlachoutsis S. Shear correction factors for plates and shells. Int Numer Methods Eng 1992;33:1537-52.

[28] Sze KY. Predictor corrector procedures for analysis of laminated plates using standard Mindlin finite element models. Compos Struct 2000;50:171-82.

[29] Timoshenko SP, Woinowsky-Krieger S. Theory of plates and shells. New York: McGraw-Hill; 1959.

[30] Nguyen TK, Sab K. and Bonnet G., A Reissner-Mindlin model for functionally graded materials. In: Proc of 3th European conf on Computational Mechanics, Lisbon, 6-2006.

[31] Vel S, Batra RC. Exact solution for thermoelastic deformations of functionally graded thick rectangular plates. AIAA J 2002;40.

[32] Nguyen VT, Caron JF, Sab K. A model for thick laminates and sandwich plates. Compos Sci Technol 2005;65:475-89.

[33] Zenkour AM. Generalized shear deformation theory for bending analysis of functionally graded materials. Appl Math Modell 2006:30:67-84

[34] Zenkour AM. Buckling of fiber-reinforced viscoelastic composite plates using various plate theories. J Eng Math 2004;50:75-93.

[35] Zenkour AM. Thermal effects on bending response of fiber-reinforced viscoelastic composite plates using a sinusoidal shear deformation heory. Acta Mech 2004:171:171-87.

[36] Zenkour AM. Analytical solution for bending of cross-ply laminated plates under thermo-mechanical loading. Compos Struct 2003;65: $367-79$.

[37] Zenkour AM. A comprehensive analysis of functionally graded sandwich plates: Part 1 - Deflection and stresses. Int J Solids Struct 2005; 42:5224 42 .

[38] Zenkour AM. A comprehensive analysis of functionally graded sandwich plates: Part 2 - Buckling and free vibration. Int J Solids Struct 2005:42:5243-58.

[39] Grujicic M, Zhang Y. Derivation of effective elastic properties of twophase materials using Voronoi cell finite element method. Mater Sci Eng A 1998;251:64-76.

[40] Zienkiewicz OC, Zhu JZ. The superconvergent patch recovery and a posteriori error estimates Part 1: The recovery technique. Int J Numer Methods Eng 1992;33:1331-64. 